RESEARCH ARTICLE

\title{
Mobile Nomadic Digital Identity
}

Naeema Abdelgawad

Englsih Language and Translation Department, Qassim University, Saudi Arabia

\begin{abstract}
Discussing the concepts of nomadism and cultural identity is the threshold to understanding the dynamics of the digital world. Nomadism as a concept that refers to the common traits shared by wandering individuals who lack sense of belonging to the spaces to which they move or leave behind. For a nomad, cultivating a distinct identity is a remote possibility; the personal traits and tendencies of nomads vary whenever they move because coping with new spaces is vital. Considering cultural identity both as a term and concept, it refers to communal traits cultivated by the members of a certain community/society over long periods of time. Such traits, which are transferred from a generation to another, become the definitive characteristics stamping the members of that space. The article seeks to spot the conflicting attitudes between the concepts of nomadism and cultural identity in a digital context. In the light of the accelerating societal and geopolitical changes imposed by the dialectics of the current digital realm, Deleuze and Guattari's standpoint on nomadism and Hakim Bey's concept of temporary autonomous zone are expounded to unveil the complexity of cultivating a definite cultural identity in the modern digital era.
\end{abstract}

Keywords: identity, deterritorialisation, re-territorialisatin, digital, space

\section{Introduction and Review of Related Literature}

Identity is the outcome of societal and cultural circumstances that are central in a specific community till they become the landmark of its membership. An identity is a layered entity that is regarded as a "composite of social relations and roles and the resulting social behavior and self-concept" (Jung \& Hecht, 2004, p. 267). Establishing a distinguished cultural identity requires belonging to a certain social group whose layers are "a multiplicity of sources - from nationality, ethnicity, social class, community, gender [ . . it] gives us a location in the world and presents us the link between us and the society in which we live" (Woodward, 1997, pp. 1-2). In this sense, the basic condition of cultivating a distinguished cultural identity is being attached to a social group. Notably, cultural identity and national identity are not the same: 
Cultural identity ... is a broader concept than national identity and only partly determined by it. Cultural identity is based on the distinctiveness or specificity of a given community, encompassing certain characteristics common to its people. (Karjalainen, 2020, p. 1)

Cultural identity creates interplay between the past and the present of a certain community. It might be affected by outward changes over the course of time, but it can never be blurred.

Cultural identity is static and integral; however, it is subject to the discursive changes in cultural milieu. The constant processes of cultural changes help shape and re-shape human attitudes, in one way or another; therefore, they become responsible for significant behavioral change. Gordon (1997 in his essay "Cultural Identity and Behavioral Change" explains how recursive changes in culture influence human behavior. He asserts that "when we speak of culture, we are speaking of both the cause and the product of human affect and cognition" (1997). Notably, changes in culture impact human activity and "provides the stimuli and the consequences of human behavioral patterns" (Gordon, 1997). In this sense, Berry, Candis and Reese discuss that multi-layered experiences are acquired because of the variety of socio-cultural spaces that have "the significant potential of shaping one's identities" (2013, p. 45). Within this context, cultural identity in the digital era is distracted from its original, and traditional course to the extent that cultural identity, somehow, tends to become more reclusive because of the modern domineering new horizons of digital knowledge and parallel virtual space that are expected to force traditional aspects of real life to go behind the scene. The gates of the new real; namely, the domineering virtual realm, are open and are about to embrace all the social brackets because of the monstrous spread and use of Smartphone technology that has facilitated cultural reclusiveness, in other words, "nomadism" in the virtual realms, while complicated sane human integration in almost all the aspects of the traditional space of real-life, as Poshka (2014) and Poepsel (2018) expound. Remarkably, the real-life cultural space that has ever been the incubator of distinct cultural identities became on the edge because of the pandemic spread of the digital realm that imposes the virtual space as the new real. The article targets underlining the rigorous process of re-molding the well-known processes of cultural identity creation within the new digital context and hopes to add to the socio-philosophical studies touching the dialectics of the accelerating digital world.

\section{Discussion}

Considering nomadism, it is some kind of plasticity that allows people to fit themselves in whatever cultural arena they move to. A " Nomad' stands for the stateless subject and habitus" (Engebrigsten, 2017, p. 45). Thus, nomads cultivate multiple, and sometimes, contradictory array of concepts and attitudes at the top of which is deterritorialisation that catalyses a special relationship with state. 'It is true that the nomads have no history, they only have a geography' (Deleuze \& Guattari, 1987, p. 393). This "geophilosophical" concept emphasizes that "nomadism exceeds the ancient rhetoric of the subject because its disposition belongs to the multiple and to the environment in which it can unfold" (Villani, 2019, p. 516). It is a "deterritorialization" that provides a nomad with freedom and an ability to think outside defined and striated space of the State where "movement" is confined and limited 
(Deleuze \& Guattari, 1987, p. 253). A nomad's space is a "smooth" social structure that defies the bureaucratic "striated" space of the state where "preset paths between fixed and identifiable points" are avoided because a nomad's space is 'smooth,'or 'open-ended"' (Massumi, 1992, p. 6) that surpasses race and ethnicity and destroys the norms of the distinctiveness and specificity of a given community. In accordance, nomadism is resistance to domination and authority.

The concept of "nomadism" that Deleuze and Guattri developed intersects with Hakim Bey's anarchic perspective that advocates the creation of a "temporary autonomous zone" a "site of resistance designed for an era in which the State is omnipresent and all-powerful and yet simultaneously riddled with cracks and vacancies" (Bey, 2003, p. 302). Bey's medium is invoking nomadology, specifically psychical nomadology, to justify resistance to the domineering and gravitational authorities, including communal identity, and, also, to establish a practice of picking up whatever one needs from the communal constants and systems while rejecting behind the unappealing parts. Accordingly, a temporary autonomous zone "TAZ" is the threshold of "the experience of free, unmediated human interaction outside the structures of State power" (Pejcha, 2020). It is a territory of experiencing freewill in an existential manner because in a temporary autonomous zone freedom is not sought at the periphery of the society; on the contrary, it is a space where personal demands are expressed while under the hegemony of the domineering power structure.

Hakim Bey prefers to prompt psychic nomadism because it has the capability to deterritorialise and re-territorialise an autonomous zone; consequently, such an autonomous zone becomes a temporary one. Deleuze and Guattri have also expressed the same concept when describing the nomad space. They assert, "The nomad has a territory; he follows customary paths; he goes from one point to another; he is not ignorant of points . . . But the question is what in nomad life is a principle and what is only a consequence' (Deleuze \& Guattri, 2010, p. 43). Deleuze \& Guattri as well as Hakim Bey coincide that the territory of the nomad, where he develops his identity, is mobile.

The contemporary digital space promotes for a nomadic culture and nomadic identity in a way compared to Deleuze and Guattri's concept of the nomad space and Hakim Bey's definition of the temporary autonomous zone (TAZ). In the nomad space, multi-layered identity does not exist; it is superseded by multiple identities that fit the practice of constant wandering "across the globe, and even beyond it through communication satellites, without necessarily moving our bodies at all" (Poster, 1990, p. 15). Nomadism in the third millennium is accelerated by a strong world internet signal which propels modern man to adopt a life of voluntary nomadism. The over-domineering internet web reterritorialises the space of the modern man by advocating a new digital culture where autonomous temporary zones are generated by infinite knowledge, business and social interaction websites.

The digital space does not marginalize any of its members, including those who prefer living at the fringes of the real world that is domineered by the "striated" authority of the "State" (Massumi, 1992 , p. 6). Unlike the members of the striated State, the members of the digital space who represent the modern type of nomads are active participants in the digital temporary autonomous zones where the inhabitants of the globe are factionalized into wandering tribes who move across innumerable websites 
and social networks. The shared objective of those tribes is following momentary interests; yet, after accomplishing the task, they move to another website or social network to achieve/search for another goal, or just surf them aimlessly. Though the wandering tribes of the digital space share similar perspectives, they prefer nomadism to integration and solidarity. This situation that would seem peculiar to the inhabitant of the real world is ascribed to the fact that "the Net's lack of spatiality, it's lack of density and its ability to maintain distance between people . . . appear to be counterproductive to solidarity" (Jones, 1997, p. 254). The modern digital identity is one of "strike and run away" that would "keep moving the entire tribe" to follow "only data in the Web" (Bey, 2003, p. 102). The digital identity of the modern nomads is compared to their space that "is localized and not delimited" (Deleuze \& Guattari, 2010, p. 46). The digital culture grants the nomads immensurable sets of identities that enable them to glide smoothly from one website to another.

The new digital media creates an interactive relationship between the modern wandering nomad and the modern digital media. A nomad in his digital territory is assigned the right to speak and express his opinion in a myriad of styles without being legally accused of adopting attitudes that oppose the striated rules of the State. The virtual freedom that is offered in the deterritorialising digital zones attracts all the categories of the real-life societies. The new "e-infrastructure" hypes the significance of the digital media and "re-shapes" not only the process of knowledge discovery, but also the re-discovery of unfathomed aspects of human personality (Nielsen, 2011, p. 26). Digital media engenders "rapid pace of developments around the exploitation of new forms of data" (Corti \& Fielding, 2016). In corollary, the paradigms of understanding the essence of anyone's identity are not mainly focused upon their reallife activities or their affiliation to some society or league but rather defined through the logging on/surfing specific websites; membership of certain social interaction platforms; the posts they share; the type of posts that win their likes and the content of their comments.

In the course of just a couple of decades, the new digital space created for itself in its virtual space a type of digital authority whose hegemony and domination emulates the real-life striated State authority. The strict regulations of the digital space forces the digitized nomads to follow its standards and orders, or else, they would be expelled, in other words, banned/blocked, and, consequently, deprived of their favorite social interaction platforms and websites. The modern digital realm outlines the identity of its members through what they write and share on the web. The posts on the timelines of the members of the social interaction platforms turn into influential gurus that teach all the brackets of people sets of principles and behavioral attitudes compared to those imbued by real world capable mentors, yet, the difference is that those principles and attitudes fit the digital nomadic tribes. The type of knowledge disseminated on the web is so engaging to the extent that modern generations prefer to neglect the knowledge, values and principles that they have been taught at the hands of cultural and religious groups; despite the fact that such groups are the principal organs that formulate and re-formulate the ideologies of any society, normally, in a positive manner. The virtual digital space has established itself as a glamorous State that has been reterritorialised by nomadic individuals who belong to all types of social brackets in the entire globe. The internet as a temporary autonomous zone has become a compensatory abode whose sedentary citizens enjoy a smooth-striated territory. 
Remarkably, the principles, ideologies, economic and socio-political conditions of any territory define the cultural traits of the identity of its sedentary people. In addition, this identity is affected by various factors, at the top of which are: social class, education, profession, family, language, religion, race, skills, and political ideology. Nonetheless, the digital media is extensively powerful because it has the power to defy all such definitive factors and is also capable of prompting new paradigms for the digital cultural identity. For instance, the Tik Tok application is designed to be an open forum that gives voice for the voiceless. Yet, its cheesy content has become extremely popular to the extent that it could suppress the original objective for which the application was invented. Digital cultural identity can also designate as inappropriate/marginal any vital element in the normative cultural paradigms, such as education, social class, race, religion, color, etc., whenever it underlines that element as inappropriate. This potentiality is the outcome of using "the internet and mobile technologies to turn information and communication into an interactive channel of communication" (Mishra, 2017, p. 611). The digital open forums are so powerful and penetrating that they can smoothly and swiftly be disseminated among all the age brackets. Thus, these forums are capable of challenging the existing structures of power and hierarchy. Therefore, the digital open forums are competent to easily transform deep-rooted cultural aspects because of the "massive expansion of the nature and quantity of information that is published" (McKee, Schalkwyk \& Stuckler, 2019). In other words, the data and information on the digital open forums are able to rapidly conquer the entire globe and persuade its inhabitants to adopt new dogmas or reject distinct traditions.

Smart phones, currently, serve as a magical gate to the widely-appealing digital temporary autonomous zone of the Internet, as with only one click man would easily belong to one or more social interaction platforms, knowing that they would be accessible provided a smart mobile phone connected to the Internet is available. Like a nomad with super powers, man through his/her smart mobile phone may swiftly move from one world community to another. Furthermore, in each new community, he may easily switch his/her identity and adopt brand new one(s) that matches the objectives of that website/forum. The digital virtual world renders societies into primitive ones: "Primitive, segmentary societies have often been defined as societies without a State, in other words, societies in which distinct organs of power do not appear" (Deleuze \& Guattari, 2010, p. 7). As for the digitized nomads who take a refuge of those societies, they follow whatever posts that share appealing principles. In accordance, digitized nomads feel that such principles are appropriate enough to apply and follow. Moreover, they almost deliberately neglect any sort of complex regulations that would make "the formation of the State apparatus both possible and inevitable", no matter if that State were a favorite digital community. Compared to primitive people, the digitized nomads "don't understand" so "complex an apparatus" (Deleuze \& Guattari, 2010, p. 7), they prefer anarchic and unplanned for attitudes and affinities.

\section{Conclusion}

Currently, the new mobile digital identity, which has been molded because of the overwhelming virtual world, has almost become the genuine definitive identity while the actual cultural identity, which is born and developed in the real life, has retreated and is on the way to be deemed an annex. In the real world, understanding the versatile perspectives of any cultural identity requires a process of unearthing 
the past to trace back the circumstances that have influenced the ancestors and have been transferred to the descendants. Undoubtedly, this is a harsh task. As for the new mobile digital identity, it has severed all its affinities with the past. It favors diasporic spirit and nomadic tendencies; characteristics that are appealing to the overpopulated digital circles.

\section{References}

[1] Berry, T. R., \& Candis, M. R. (2013). Cultural identity and education: A critical race perspective. Educational Foundations, 27(3-4), 43-64. https://eric.ed.gov/?id=EJ1065655

[2] Bey, H. (2003). T.A.Z.: The temporary autonomous zone, ontological anarchy, poetic terrorism $\left(2^{\text {nd }}\right.$ ed.). Autonomedia.

[3] Corti, L., \& Fielding, N. (2016). Opportunities from the digital revolution: Implications for researching, publishing, and consuming qualitative research. SAGE Open. doi: $10.1177 / 2158244016678912$

[4] Deleuze, G., \& Guattari, F. (1987). A thousand plateaus: Capitalism and schizophrenia (B. Massumi, Trans.). The University of Minnesota Press.

[5] Deleuze, G., \& Guattari, F. (2010). Nomadology: The war machine (B. Massumi, Trans.). Wormwood Distribution.

[6] Engebrigsten, A. I. (2017). Key of mobility: The nomad. Social Anthropology, 25(1), $42-54$. https://doi.org/10.1111/1469-8676.12379

[7] Gordon, E. W. (1997). Cultural identity and behavioral change. Case Western Reserve Law Review, 47(2), 389-398. https://scholarlycommons.law.case.edu/caselrev/vol47/iss2/6

[8] Jones, S. G., (Ed.). (1997). Virtual culture. Identity and communication in cybersociety $\left(1^{\text {st }}\right.$ ed.). Sage Publications.

[9] Jung, E., \& Hecht, M. L. (2004). Elaborating the communication theory of identity: Identity gaps and communication outcomes. Communication Quarterly, 52(3), 265-283. https://doi.org/10.1080/01463370409370197

[10] Karjalainen, H. (2020). Cultural identity and its impact on today's multicultural organizations. International Journal of Cross Cultural Management, 20(2), 249-262. https://doi.org/10.1177/1470595820944207

[11] Massumi, B. (1992) A user's guide to capitalism and schizophrenia. Deviations from Deleuze and Guattari. Massachusetts MIT Press.

[12] McKee, M., van Schalkwyk, M. V., \& Stuckler, D. (2019). The second information revolution: Digitalization brings opportunities and concerns for public health. The European Journal of Public Health, 9(3), 3-6. doi: 10.1093/eurpub/ckz160 
[13] Mishra, K. D. (2017). Social media revolution - The new digital frontiers of journalism. Journal of Advances in Humanities, 5(1), 610-620. doi: 10.24297/jah.v5i1.6068

[14] Nielsen, M. (2011). Reinventing discovery: The new era of networked science. Princeton University Press.

[15] Pejcha, C. S. (2020, August 19). Better living through anarchy: Tracking the rise of the temporary autonomous zone. Document. https://www.documentjournal.com/2020/08/betterliving-through-anarchy-tracking-the-rise-of-the-temporary-autonomous-zone/

[16] Poepel, M. (2018). Media, society, culture and you: An introductory mass communication text. Rebus Community.

[17] Poshka, A. (2014). Digital culture and social media versus the traditional education. Journal of Education Culture and Society, (1), 201-205 doi: 10.15503/jecs20141-201-205

[18] Poster, M. (1990). The mode of information. Poststructuralism and social context. The University of Chicago Press.

[19] Villani, T. (2019). Gilles Deleuze: Philosophy and Nomadism. Deleuze and Guattari Studies, 13(4), 516-527. https://doi.org/10.3366/dlgs.2019.0377

[20] Woodward, K. (Ed.). (1997). Identity and difference. Sage Publications. 